\title{
DOMICILIARY CARE PROVIDERS VIEWS ON PROVISION OF PALLIATIVE CARE FOR THEIR CANCER PATIENTS
}

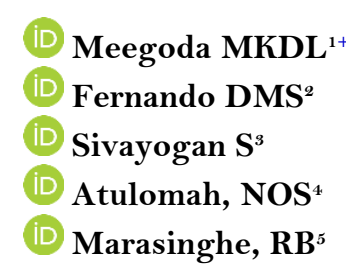

${ }^{3}$ Email:shivyom@yahoo.com

Department of Public Health, Babcock University, Ogun State, Nigeria ${ }^{*}$ Email:nnodatulomah@hotmail.com

Department of Medical Education, Faculty of Medical Sciences, University of Sri Jayewardenepura, Sri Lanka

${ }^{5}$ Email: rohanabm@yahoo.com

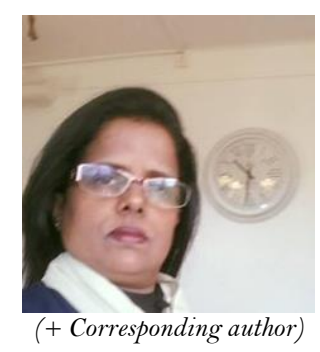

ABSTRACT

A qualitative study was conducted to describe views and life experiences of domiciliary care providers in meeting the palliative care needs of adult cancer patients at the National Cancer Institute, Maharagama, Sri Lanka. The target population for this study was Domiciliary Care Providers (DCPs) who were the family care givers of patients at National Institute of Cancer, Maharagam (NICM), Cancer Home (CH), Maharagama, Shantha Sevana Hospice (SSH) and Ceylinco Oncology Unit (COU), Colombo, Sri-Lanka. Purposive sampling technique was used to select participants for the study. In-depth interviews were conducted using validated semi-structured interviewer guide. Data saturation was reached after 15 in-depth interviews with DCPs. Trustworthiness of the study was maintained. Phenomenological-hermeneutic approach was followed to analyze qualitative data and thematic analysis was performed. Data analysis was done concurrently with data gathering. Being reassured, having more expectations, need psychosocial help and inadequate knowledge were the key themes identified. They expect knowledge improvement to provide better care. As patients' level of satisfaction on domiciliary care provided by DCPs was high, improving their knowledge on palliative care may be a cost effective method of improving palliative care.

Contribution/Originality: This study makes the distinct contribution to existing body of knowledge on the effectiveness of an educational intervention on cancer palliative care for nurses. This study uses new estimation methodology of implementing a user friendly intervention delivered through hybrid delivery. This study originates new formula in palliative care nursing. It used printed material on cancer palliative care, supplemented with face to face interactive sessions, DVD, telephone and online communications. This study is one of very few studies which have investigated improvement of nurses' skills in cancer palliative care using quasi experimental design. The paper's primary contribution is finding that nurses skills improved significantly from the baseline to outcome evaluation and compared to the control group there was a 7.9 fold increase in the skills of nurses following the 
intervention. This study documents the effectiveness of an educational intervention on cancer palliative care delivered through a hybrid model.

\section{INTRODUCTION}

The terminally ill requires palliative care (PC) with a holistic approach. PC addresses patients' physical, psycho-social, spiritual and emotional needs [1]. The word palliative comes from the Latin word "pallium" meaning cloak or cover [2]. The basic philosophy of palliative care is to achieve the best quality of life for patients even when their illness cannot be cured. PC is provided through comprehensive management of the physical, psychological, social, and spiritual needs of patients, while remaining sensitive to their personal, cultural and religious values and beliefs. It is an approach that improves the quality of life of patients and their families facing the problems associated with life threatening illness, through the prevention and relief of suffering by means of early identification and impeccable assessment and treatment of pain and other problems, physical, psychosocial and spiritual [3].

According to the world cancer report [4] prevalence of cancer is increasing at an alarming rate globally. Cancer is the second leading cause of death globally and accounted for 8.8 million deaths in 2015. Lung, prostate, colorectal, stomach and liver cancer are the most common types of cancer in men, while breast, colorectal, lung, cervix and stomach cancer are the most common among women [4]. Approximately 17 million new cases are projected for 2020 [5]. More than $70 \%$ of all cancer deaths occur in low and middle income countries, where resources available for prevention, diagnosis and treatment of cancer are limited or nonexistent [3]. The majority of cancer patients are in advanced stages of cancer when first seen by a medical professional. For them, the only realistic treatment option is pain relief and palliative care. Thus PC is an essential part of cancer control, both for adults and children [4]. Across Sri Lanka there is a rapid rise in adult cancers of all types. It is estimated that 18,000 new cases of cancer were reported for the year, 33\% of them ending in death within a year [6].

The limited availability of palliative care services within or outside the hospital makes it difficult for the patients and their families to go through the terminal phase of the disease and dying. These infrastructure and personnel shortfalls are observed even in many developed countries like the USA and Germany [7, 8]. To overcome this problem of providing adequate care to patients who needs these intervention, countries like Sri Lanka allow domiciliary care providers (DCPs) to stay with the patients to look after them at their bedside and also they look after the patients at their own home. Furthermore a sustainable approach to prevent the need for unnecessary institutionalization of cancer patients and maintain individuals in their home and community as long as possible is important to maintain patients' quality of life while remaining DCPs quality of life.

Most of the DCPS in Sri Lankan Cancer patients are patients' family members. Although a caregiver may not have a medical background, daily contact with the patient gives the caregiver important information that helps the health care team and help the patient. The family caregiver will often take on the role of talking for the patient while keeping the patient included in decision making. DCPs are individuals who provide uncompensated care or assistance to a family member who is suffering from the symptoms of cancer [9]. Therefore identify the DCPs views on the patient's care is essential to determine whether the patients receive required care at home. On the other hand as caregivers try to meet the physical demands of caregiving, they may not get enough rest and may not take care of their own health. Family caregivers often neglects their own quality of life by putting the patient's needs first [10]. However family caregivers often feel unprepared to provide care [11]. Due to unpreparedness they have inadequate knowledge to deliver proper care, and receive little guidance from the formal health care providers [11] to maintain quality of life of the patients. These caregivers are not adequately trained in how to help the patient to manage side effects of treatment and symptoms such as pain and fatigue [10] though the family caregivers take an active role that begins when the cancer is being diagnosed. It has been reported that when the 
caregiver is trained in how to help the patient to manage side effects of treatment and symptoms such as pain and fatigue, the patient is more likely to have the energy and will to continue with treatment [10].

Palliative care provided by nurses, other health care professionals and domiciliary care providers improves the quality of life of patients and their families facing life-threatening illness by providing pain relief and management of other distressing and unbearable symptoms [12]. From the time of diagnosis of a life-threatening illness and throughout the course of the illness palliative care services are applicable. Explore DCPs views on their current practices at home and at the institutions and their views about their patients' needs is essential to identify whether the patients and family care givers needs were being fulfilled. However only very limited literature on this area of study was found in Sri Lanka. Current study aimed to describe the knowledge and perceptions regarding patient care of domiciliary care providers. The study also explore the DCPs views on palliative care needs of their cancer patients.

\section{METHOD}

This was a qualitative study of male and female DCPs who were the main care-givers of cancer patients. Purposive sampling technique was used to select participants from NICM, CH, SSH and COU, Colombo, Sri-Lanka. The National Center for treatment of patients with cancer is the premier tertiary care hospital dedicated for the diagnosis, treatment and follows up of cancer patients. In-depth interviews were conducted using semi-structured validated interviewer guide. Interviews lasting for about 30minutes were recorded using an audio device. The contents of the audio recordings were transcribed verbatim and themes were developed based on research question $\mathrm{s}$ and study objectives. Data saturation was reached with 15 interviews with 15 domiciliary care providers. Ethical approval was obtained from the ethical review committee of the faculty of medical sciences, University of Sri Jayewardenepura.

\section{DATA ANALYSIS}

The significant statements and concepts of the transcripts were highlighted to identify the thematic areas. Themes were identified by manual coding and then thematic analysis was done. Data analysis was done parallel to data gathering and results were strengthened with memorable quotes and facial expressions of the participants.

\section{RESULTS}

The researcher purposively recruited male (43.75\%) and female (56.25\%) participants. The age range was 16 and 63 years. Content analysis of in-depth interviews with DCPs yielded four key themes namely, being reassured, having more expectations, need psychosocial support and inadequate knowledge. DCPs were patient's family members.

\subsection{Being Reassured}

DCPs are always under stress due to not being prepared for care giving. Reassurance of DCPs should be done by the nurses at the hospital or any health care facility and by the other family members at the home.

Narratives of the DCPs revealed that they were well reassured by the nurses and patients other family members. Reassurance was needed to have a peaceful mind.

However, some issues still needed to be reassured.

"This is my first time caring for a patient. Doctors tell us to give him more fluids. Now my father cannot tolerate any food. Just after having tea he vomits (tears). When we give more fluids my father gets angry with me." (DCP - 4).

Economically we are unstable, so I have to save my job. I don't have leave to look after her. If I could not give enough care to her I feel sad. I am married, I have to look after 
my children and my husband. To give care to these patients we need more strength in mind (DCP-3).

"Sometimes she passes urine and stools on the bed, and then I clean. It was very difficult for me because I don't know how to clean her while she is on the bed. I don't know how to identify or to ask questions in order to identify the needs of the patient early" (DCP 11).

DCPs had to look after their family member along with providing palliative care, because they cannot tolerate the suffering of the family member.

\subsection{Having More Expectations}

DCP's desired to provide care to their patients in a holistic manner and wanted to deliver the best to the patients despite their own problems.

"Her drugs are not available, so I am worried about that, because I know without the drugs her condition will deteriorate" (DCP-1).

DCPs wanted their patient (Family member) to have long life, and quality of life

"We live because of our parents, it is they who brought us up to this level. So we have to look after them well. I have been providing care to my mother for five years. I want to keep my mother happy and expect early cure by giving good care" (DCP-5).

\subsection{Need Psychosocial Help}

“"While staying with the patient we always think of the condition of the patient and how to help the patient. We do not have time to watch Television or to read" (DCP-13).

"She worries because I am not married. I told her not to worry about me and I will face any challenge. Because she is my mother I am caring for her willingly. She is thinking about my father too, because he has a heart problem. When other patients shout in pain she inquires 'what is that?' She thinks that the patient is dying. She is afraid of dying. I cannot bear to see her suffering" (DCP-12).

"I have 4 children, I was told that one of my children has attempted suicide by taking poison, but I do not know the reason. The patient whom I am looking after is my mother -in-law. I cannot give up on my mother-in-law (Patient) as well but I am worried whether the other members of my family will look after my daughter well" (DCP-6).

DCPs have to face their own social problems. They continue to care with these social problems, with a feeling of lost expectations as they believe cancer is incurable. DCPs believe patients' psychological status should be well maintained. Most of them believe breaking bad news to the patient is not favorable for the patient's psychological status. All of the DCPs at Ceylinco Oncology Unit which is a private institution were family members and some of them felt the financial drain due to prolonged hospitalization which leads to further psychological problems.

\subsection{Inadequate Knowledge}

"I do not have any training. I do not have experience either. If I cannot give adequate care to her I feel unhappy. I just help her when she requests assistance in feeding, washing, grooming and toileting” (DCP - 1).

"Strengthening patient's mind is very important to maintain their quality of life. We must have knowledge to support our patients to handle emotional problems."(DCP-13).

"I do not understand what her needs are if she cannot tell. We think patient's sleep is not more important than drugs. We have to identify their needs and provide care 
accordingly. When she has difficulty in breathing, I can identify it and raise her head and then inform nurses. I was not given information regarding her care anyway" (DCP $-10)$.

I cared for my mother for five years. I prepare meals, orange and eggs for her, but still I need more knowledge to provide better care, because I give care through experience. I still don't know the exact methods for pain reduction which is essential" (DCP - 7).

DCP's expect to gain knowledge on cancer palliative care from the nurses to avoid facing difficult situations which were challenging to handle alone. Most of the DCPs continue providing care with no previous experience. DCP's revealed that basic facilities like a place to have proper sleep were not available but still they continue to care.

\section{DISCUSSION}

Domiciliary care providers provide care to individuals who require bed side care at the home, hospice or at the hospital. Their services include offering medications, providing basic daily activities like bathing, feeding and grooming together with providing psychological, social and spiritual support. As described by Sherwood, et al. [13] most care givers were females and family members of the cancer patient and aged 55 years or older. According to the current study DCPs need psychological support and more knowledge to provide care for their patients. They also have their own expectations. Hence reassuring of them with psychological support is very effective to improve their health and it will help to improve cancer patients care provided by family members. Freedom to provide care and providing enough resources especially economical support are also important, because they provide care willingly. DCPs seek knowledge on cancer palliative care from the nurses who provide care for their patients.

The DCPs expressed the need for relaxation while caring for the patients, but in the institutions where this study was conducted, the facilities available were minimal. Except for the private institution, even the basic facilities to have adequate sleep were not provided by the institution. Similar results were found by Kulkarni, et al. [14] where a large number of caregivers in Cipla Palliative Care Center, India reported feeling continually tired and exhausted. Reinhard, et al. [15] have also reported that family caregiving can be stressful. Stress can adversely affect both the caregiver and the care recipient. Hence upgrading facilities for DCP's to rest and relax in the institutions where the cancer patients are hospitalized is recommended as a measure of improving overall care.

Domiciliary care providers expressed the need for knowledge on palliative care, as they are the immediate contact with the patients. The long duration of the commitment was another concern. Scherbring [11] also reports that family care givers often feel unprepared to provide care, have inadequate knowledge to deliver proper care and receive little guidance from the formal health care providers. Due to inadequate knowledge and skills, family caregivers may be incompetent in providing the quality of care or the quantum of care needed [15]. As evident by the results of the current study and those reported by others, educating the care providers is imperative to improve quality of care. This has been emphasized by Sherwood, et al. [13] who suggested to do interventions to improve caregivers' knowledge and emotional health.

DCPs in this study seem to have learnt about the disease condition and the required care mainly from doctors and nurses. In the current study one of the DCPs expressed that "Patients condition varies. So we have to listen to nurses and other health care workers about patients care, because they are the ones who know patients care well". Family members trust the nurses on the information about the patient's condition. On the other hand nurses are answerable to the activities of DCPs on the patient during the period of hospitalization and the nurses are accountable for any mistakes done by DCPs. Therefore nurses should guide the DCPs to find time and read to be more knowledgeable on the disease and provision of care. Improving the knowledge of DCPs will improve the quality of life of cancer patients. Nurses are the best suited for this task. Thus educating the family members of the patient with proper information should be given much emphasis when developing a training and an educational interventions for nurses. 


\section{CONCLUSION}

In this study the domiciliary care givers played a major role in caring for their patients. Having inadequate knowledge, experience and skills to provide palliative care were of concern to, however DCP's felt reassured. DCP's were aware of the fact inadequate knowledge and skills on providing palliative care for their patient, will adversely affect the quality of life of the cancer patients. Managing their own time and maintaining their own quality of life, was identified as important to prevent burnout. Therefore improving DCPs knowledge on palliative care may be a cost effective method of improving care.

\section{RECOMMENDATIONS}

Further research on the needs of DCPs and their pain management skill, will enhance the effectiveness of provision of holistic care for cancer patients. As the ultimate accountability for the care provided by DCPs lies on nurses who work in palliative care settings updating the knowledge of nurses on palliative care including nonpharmacological methods is essential. It was assumed that nurses could educate DCP's at the hospital.

Funding: Funded by University of Sri Jayewardenepura (ASP/06/Re/2009/09 of 10/12/2008)

Competing Interests: The authors declare that they have no competing interests.

Contributors/Acknowledgement: All authors contributed equally to the conception and design of the study.

\section{REFERENCES}

[1] L. Kristjanson, Manias, and T. Bush, "Palliative care nursing education: Australian \& Canadian challenges," Journal of Contemporary Nurse, vol. 6, p. 950, 2008.

[2] R. Becker, "Principles of palliative care nursing and end of life care," Nursing Times, vol. 105, p. 13, 2009.

[3] Woruld Health Organization, Cancer control knowledge into action: WHO Library Cataloguing in Publication Data, 2007.

[4] World Health Organization, "World cancer report," 2017.

[5] L. Bethany and A. Judith, "Pain and palliative care needs of cancer survivors," Journal of Hospice \& Palliative Nursing, vol. 13, pp. 202-207, 2011. View at Google Scholar | View at Publisher

[6] Cancer News Center, "Programme of action for cancer therapy. [Accessed 23, May 2008]," 2008.

[7] M. Grant, R. Elk, B. Ferrell, R. S. Morrison, and C. F. Gunten, "Current status of palliative care-clinical implementation, education and research," Cancer Journal for Clinicians, vol. 59, pp. 327-335, 2009. View at Google Scholar

[8] N. Schneider, G. K. Mitchell, and S. A. Murray, Palliative care in urgent need of recognition and development in general practice: The example of Germany: US National Library of Medicine National Institutes of Health, 2010.

[9] B. A. Given, P. Sherwood, and C. W. Given, "Support for caregivers of cancer patients: Transition after active treatment," American Association for Cancer Research, vol. 20, pp. 2015-202 1, 2011 . View at Google Scholar | View at Publisher

[10] National Institute of Cancer, "The caregiver's perspective: Across the illness trajectory March 15. America," 2017.

[11] M. Scherbring, "Effect of caregiver perception of preparedness on burden in an oncology population," Oncology Nurses Forum, vol. 29, pp. E70-E76, 2002. View at Google Scholar | View at Publisher

[12] WHO, "The mission of WHO cancer control programme." Retrieved from http://www.who.int/cancer/, 2017.

[13] P. R. Sherwood, B. A. Given, C. W. Given, R. F. Schiffman, D. L. Murman, M. Lovely, A. von Eye, L. R. Rogers, and S. Remer, "Predictors of distress in caregivers of persons with a primary malignant brain tumor," Research in Nursing $\mathcal{E}^{\circ}$ Health, vol. 29, pp. 105-120, 2006.

[14] P. Kulkarni, P. Kulkarni, R. Ghooi, M. Bhatwadekar, N. Thatte, and V. Anavkar, "Stress among care givers: The impact of nursing a relative with cancer," Indian Journal of Palliative Care, vol. 20, pp. 31-39, 2014. View at Google Scholar View at Publisher 
[15] S. C. Reinhard, B. Given, N. H. Petlick, and A. Bemis, "Supporting family caregivers in providing care. Patient safety and quality: An evidence-based handbook for nurses," presented at the National Center for Biotechnology Information, U.S. National Library of Medicine, 2008.

Views and opinions expressed in this article are the views and opinions of the author(s), Cancers Review shall not be responsible or answerable for any loss, damage or liability etc. caused in relation to/arising out of the use of the content. 